\title{
Luz, arte, ciência... ação!
}

\section{Lights, art, science-action!}

\section{Thelma Lopes}

Coordenadora do Ciência em Cena, espaço do Museu da Vida Casa de Oswaldo Cruz/Fiocruz Av. Brasil, 4.365

21040-900 Rio de Janeiro - RJ thelmalopes@hotmail.com
LOPES, T.: Luz, arte, ciência... ação! História, Ciências, Saúde - Manguinhos, v. 12 (suplemento), p. 401-18, 2005.

O principal objetivo do presente artigo é refletir sobre as principais interações entre teatro, ciência e tecnologia, ao longo da história do teatro, e discutir, a partir de nossa experiência no Ciência em Cena, espaço integrante do Museu da Vida, de que modos essas interações podem estar presentes no cotidiano de um museu de ciências. A palavra 'ciência' deve ser compreendida aqui em sentido amplo, englobando não apenas as ciências naturais, mas também as ciências humanas, assim como a palavra 'tecnologia' deve ser associada à ciência aplicada. Arte e ciência serão entendidas como processos criativos, como formas de representação do mundo e expressão do conhecimento humano.

PALAVRAS-CHAVE: arte e ciência, iluminação cênica, tecnologia cênica, arte em museus de ciência.

LOPES, T.: Lights, art, science - action!

História, Ciências, Saúde - Manguinhos, v. 12 (suplemento), p. 401-18, 2005.

The article offers some reflections on the main interactions between theater, science, and technology down through the history of theater. Based on our experience at "Science in the Spotlight", part of the Casa de Oswaldo Cruz's Museum of Life, we discuss how these interactions can be part of a science museum's daily activities. We use the word 'science' in its broad sense, encompassing not only the natural but human sciences as well; likewise, we use the word 'technology' as it relates to applied science. Art and science are understood here as creative processes, as ways of representing the world and expressing human knowledge.

KEYWORDS: art and science, stage lighting, stage technology, art in science museums. 
Os aparelhos luminosos atualmente em uso nos teatros não bastam mais. Como a ação particular da luz sobre o espírito passa a fazer parte do jogo dramático, novos efeitos de vibrações luminosas devem ser procurados, novos modos de difundir a iluminação em ondas, ou em camadas, ou como uma chuva de flechas incendiárias. A gama colorida dos equipamentos atualmente em uso deve ser revista de cabo a rabo. A fim de produzir qualidades de tons particulares, deve-se introduzir, na luz, elementos de corpo, densidade, opacidade, com o objetivo de produzir calor, frio, raiva, medo etc.

(Antonin Artaud, 1984, p. 122.)

\title{
Arte e ciência: um namoro antigo
}

A Arte é longa, a vida é curta. (Hipócrates, apud Frederico Morais, 1998, p. 209)

\begin{abstract}
$\Delta$ i o longo da história das artes, podemos verificar diferentes interações entre arte e ciência. Enfocaremos principalmente a relação entre teatro e ciência, porque o teatro é uma linguagem artística que congrega várias outras artes, como a música, o cinema ou a pintura. Portanto, de certo modo, na medida em que refletimos sobre o teatro estaremos incluindo outras artes. Outra razão para relacionar a ciência ao teatro refere-se ao fato de que a ciência é em si dramática. A ciência possui teatralidade própria porque o exercício da atividade científica pode envolver grandes controvérsias, disputas, ambição, argumentação, contra-argumentação, enfim, todos os elementos para uma excelente peça dramatúrgica.

Antes de nos debruçarmos sobre a relação teatro e ciência, vale a pena abordar, ainda que brevemente, relações entre ciência e tecnologia e outras modalidades de arte. A música, associada à ciência desde Pitágoras, atualmente guarda uma forte interação com a tecnologia, com a produção de sintetizadores e samplers que incrementam a multiplicação de inusitados sons em uma mesma composição musical e barateiam os custos de produção e reprodução. A relação entre música e tecnologia não apenas influencia a linguagem musical como também acarreta a discussão sobre novas questões relativas à produção musical e ao mercado, tais como a multiplicação das músicas e partituras via Internet e os direitos autorais.

Nas artes plásticas a relação entre arte e ciência também é antiga, e nesse âmbito podemos citar o uso que os renascentistas fizeram da matemática. Os pintores da época aplicavam princípios da
\end{abstract}


matemática para conferir ilusão de volume, textura e proporção harmoniosas no intuito de reproduzir as feições anatomicamente corretas, em uma tentativa de retratar fielmente o corpo humano. Em 1632, Rembrandt pintou seu famoso quadro Lição de anatomia. A combinação entre arte e anatomia era uma via de mão dupla, pois também os médicos recorriam aos artistas renascentistas, que registravam graficamente, e com especial precisão, as dissecações anatômicas. Se dermos um pulo no tempo e pensarmos em Escher (1898-1972), identificaremos que o pintor holandês utilizou princípios da geometria na busca de reproduzir a noção de infinito. Diferentemente dos pintores renascentistas, que aplicaram recursos da matemática para reproduzir um mundo à semelhança da realidade, Escher utilizou a geometria para representar um mundo fantástico, que somente poderá ser encontrado em sua instigante obra.

Se pensamos na relação entre tecnologia e cinema, é possível afirmar que esta é uma arte que só foi possível pelo desenvolvimento de equipamentos tecnológicos que envolvem desde recursos fotográficos até sofisticados equipamentos de projeção atuais. A tecnologia na indústria cinematográfica influencia diretamente a linguagem da grande tela. A sonorização de imagens é um exemplo dessa influência, assim como o advento das cores, os efeitos visuais proporcionados pela computação gráfica ou a produção de telas que geram a ilusão de 360 graus. No campo da arte teatral, podemos verificar interações com a ciência e a tecnologia em diferentes níveis. Não apenas novas tecnologias foram incorporadas à cena teatral, mas também, com Bertolt Brecht, houve a pretensão de incorporar aspectos da metodologia científica aos métodos de criação teatral.

\section{O teatro e as ciências}

- Agora mesmo você usou a expressão 'científica'. Você quer dizer que quando alguém observa uma ameba ela não se oferece ao observador humano. Ele não pode penetrar em sua pele por empatia. Contudo, o observador científico tenta entendê-la. Você acha que finalmente ele o consegue?

- Não sei. Ele tenta colocá-la em relação com outras coisas que já viu.

- Não deveria tentar fazer compreensível o homem que representa?

- Não tanto o homem quanto o que acontece. Quero dizer que se escolho Ricardo III, não quero me sentir Ricardo III, mas entender esse fenômeno em toda a sua estranheza e incompreensibilidade.

- Devemos, então, ver ciência no teatro?

- Não. Teatro. 
- Compreendo: o homem da era científica deve ter o seu próprio teatro.

- Sim. Só que o teatro já tem o homem científico na sua platéia, mesmo que nada tenha feito para reconhecer este fato. Porque o público geralmente pendura o cérebro na sala de entrada, junto com o casaco (Bertolt Brecht, 1967, p. 44).

Segundo o teórico francês Jean-Jacques Roubine (1998, p. 19), na obra A linguagem da encenação teatral,

nos últimos anos do século XIX ocorreram dois fenômenos, ambos resultantes da revolução tecnológica, de uma importância decisiva para a evolução do espetáculo teatral, na medida em que contribuíram para aquilo que designamos como o surgimento do encenador. Em primeiro lugar começou a se apagar a noção de fronteiras e, a seguir, a das distâncias. Em segundo foram descobertos os recursos da iluminação elétrica. (...) Se, por exemplo, no início do século passado, digamos até 1840, existia uma verdadeira fronteira, ao mesmo tempo política e geográfica, separando o chamado bom gosto, um gosto especificamente francês, da estética shakesperiana, a partir dos anos 1860 as teorias e práticas teatrais não podem ficar circunscritas dentro de limites geográficos nem ser explicadas por uma tradição nacional (....) Trata-se de um fenômeno de difusão que não seria correto considerar restrito aos produtos, às obras.

O encurtamento das distâncias promovido pelo desenvolvimento tecnológico contribuiu para a ampliação da difusão das mais diversas manifestações teatrais, permitindo a aproximação e a contaminação de gêneros teatrais de diferentes origens, possibilitando o aparecimento de outras estéticas no campo da arte cênica. A iluminação elétrica revolucionou a cena teatral, sendo utilizada para estruturar e animar a cena, esculpir e modelar o espaço cênico. É importante ressaltar que as condições para uma transformação no âmbito do teatro não se resumem às ferramentas técnicas, mas também ao desejo de ruptura com teorias e fórmulas superadas. $\mathrm{O}$ debate em torno da prática teatral do século XX coloca em oposição o naturalismo e o simbolismo. O primeiro objetivando levar à cena a representação figurativa do real; e o segundo, a representação do irrealismo. Enquanto o teatro naturalista pretendia reproduzir fotograficamente a realidade, o simbolista preconizava a representação subjetiva e simbólica do mundo. Na cena naturalista, o uso da luz estava relacionado à tentativa de reproduzir fotograficamente o crepúsculo ou a luz do amanhecer, por exemplo; em contrapartida, na cena simbolista a iluminação, colorida e fluida, se tornava parceira de cena e buscava criar um mundo distante do ilusionismo figurativo. 
Segundo Roubine (1998, p. 23), "este debate não seria tão intenso e fecundo, se não fosse sustentado por uma revolução tecnológica baseada na eletricidade". Hoje a iluminação apresenta numerosas funções dramatúrgicas e semiológicas, tais como: conferir ritmo à representação, comentar uma ação, isolar um ator ou elemento de cena. Segundo o teatrólogo francês Patrice Pavis (1999, p. 202), a "luz assume uma dimensão quase metafísica, ela controla, modaliza e nuança o sentido; infinitamente modulável, (...) é um elemento atmosférico que religa e infiltra os elementos separados e esparsos, uma substância da qual nasce a vida". No palco do século XX podemos verificar múltiplas formas de utilização da luz: a iluminação atmosférica de Stanislavski, a iluminação cenográfica de Appia e Craig, a utilização simbólica anunciada por Artaud na década de 1930 e praticada em 1960-70 e, paralelamente, o retorno a uma simplicidade no uso da iluminação comandado por Brecht.

Na cena brechtiana, a luz é utilizada para tornar o espetáculo visível e lembrar o espectador de onde ele está, e o lugar onde o espectador está é o 'teatro épico' - teatro desenvolvido pelo dramaturgo alemão que buscou uma intensa comunicação com a prática científica. O tema da ciência interessou Brecht profundamente e, em especial, a vida do cientista Galileu Galilei. Nenhuma das peças teatrais ocupou e apaixonou Brecht por tanto tempo como Vida de Galileu. Como observa um dos mais importantes estudiosos da obra de Brecht, John Willet (1980, p. 121), “a julgar pela proporção dos escritos dedicados a Galileu nos arquivos de Berlim, Vida de Galileu é a mais exaustivamente explorada de todas as peças de Brecht". Nenhum de seus textos dramatúrgicos atravessou tantos estágios. Por quase vinte anos a vida de Galileu Galilei fez parte da vida de Brecht, que, vendo o cenário político, social e cultural à sua volta sofrer drásticas mudanças, também fez mudar, em sua obra, a vida do cientista de Pisa. Assim, Brecht escreveu três versões principais sobre a vida de Galileu: a primeira em 1938-39, na Dinamarca; a segunda em 1946-47, na América do Norte; e a terceira nos anos de 1953-56, na Alemanha. Entretanto, precedendo a primeira versão completa, havia numerosas notas inéditas e esquetes, que sugerem uma formulação diferente das outras três. Outra importante afinidade entre Brecht e Galileu é revelada pelo próprio Brecht. Em seu diário de trabalho, em um registro do dia 12 de fevereiro de 1939, o dramaturgo declara que se inspirou na obra Diálogo concernente aos dois principais sistemas do mundo, de Galileu Galilei, para escrever A compra do latão (Brecht, 1999). O processo de escrita do Diálogo... ocupou Galileu Galilei intermitentemente durante um período de seis anos. Neste livro, o cientista italiano estabeleceu um diálogo entre três personagens, que discutem, ao longo de quatro noites, os dois principais sistemas do mundo, ou seja, o sistema geocêntrico (defendido por Ptolomeu e Aristóteles, e 
que localiza a Terra como centro do universo) e o sistema heliocêntrico (teorizado por Copérnico, que localiza o Sol como o centro do sistema solar). Os personagens criados por Galileu Galilei não são inteiramente fictícios. Na verdade, dois deles foram seus amigos íntimos e já haviam falecido: Filipo Salviati, nobre florentino, nascido a 19 de janeiro de 1582, e que hospedara o cientista várias vezes na Villa delle Selve, e Gianfrancesco Sagredo, nascido em Veneza, a 19 de junho de 1571, que foi aluno particular de Galileu em Pádua e continuou em estreito contato com ele até sua morte em Veneza, em 1620. O nome Simplício não remete a nenhum amigo de Galileu, e sim ao filósofo grego, nascido na Sicília e que viveu no VI século d. C. - Simplicius, renomado comentador de Aristóteles. Brecht, em sua peça sobre Galileu, também criou um personagem chamado Sagredo. Nesta obra, Sagredo testemunha uma importante descoberta do cientista, estabelecendo com ele uma relação de amizade e cumplicidade. Passemos ao diálogo entre Sagredo e Galileu (Brecht, 1977b, p. 47-8):

Sagredo (olhando pelo telescópio à meia voz) - Os bordos do crescente estão irregulares, denteados e rugosos. Na parte escura, perto da faixa luminosa, há pontos de luz. Vão aparecendo, um depois do outro. A partir deles a luz se espraia, ocupa superfícies sempre maiores, onde conflui com a parte luminosa principal.

Galileu - E como se explicam esses pontos luminosos?

Sagredo - Não pode ser.

Galileu - Pode, são montanhas.

Sagredo - Numa estrela?

Galileu - Montanhas enormes. Os cimos são dourados pelo sol nascente, enquanto a noite cobre os abismos em volta. Você está vendo a luz baixar dos picos mais altos ao vale.

Sagredo - Mas isto contradiz a astronomia inteira de dois mil anos.

Galileu - É. O que você está vendo, homem nenhum viu além de mim. Você é o segundo.

Em Diálogo..., podemos dizer que Salviati representa o cientista investigativo, porta-voz da argumentação de Galileu. Simplício, não por acaso assim nomeado, representa o pensamento aristotélico, e Sagredo representa um cientista pretensamente neutro. Nesta obra, Galileu Galilei opõe suas teorias à visão de mundo aristotélica e, ao mesmo tempo, argumenta em favor de um novo paradigma, baseado no movimento da Terra segundo a teoria de Copérnico. Ilustremos com um trecho de Galileu em que Salviati e Simplício conversam sobre a teoria (Banfi, 1992, p. 135): 
Simplício - Este modo de filosofar tende à subversão de toda a filosofia natural, e a desordenar e provocar a derrocada do Céu e da Terra e de todo o Universo; mas creio que os fundamentos dos Peripatéticos são tais que não seja de temer que com a ruína se possam construir novas ciências.

Salviati - Não vos preocupeis com o Céu nem com a Terra, nem temais a sua subversão, nem tampouco a da filosofia, porque quanto ao Céu, debalde temeis por ele que vós próprios considerais inalterável e impassível; quanto à Terra, procuramos nobilitá-la e aperfeiçoá-la ao procurarmos fazê-la semelhante aos corpos celestes e, de certo modo, colocá-la quase no Céu, donde vossos filósofos quase a expulsaram.

Diálogo... está dividido em quatro jornadas. A primeira contém a crítica aos princípios fundamentais da física aristotélica e aos fundamentos teológicos da teoria ptolomaica. A segunda e a terceira jornadas fazem a defesa do sistema copernicano. Finalmente, a quarta apresenta a teoria das marés, que Galileu Galilei, erroneamente, pensava ser uma prova experimental conclusiva da hipótese da mobilidade da Terra. Os textos que Brecht reuniu sob o título $A$ compra do latão resultaram de um trabalho que se estendeu por um período de 16 anos. Brecht (1999, p. 170) pretendeu que esta obra fosse "uma conversa a quatro sobre a nova maneira de fazer teatro". Seu objetivo, ao organizá-la, parece ter sido o de explicitar o conceito de um teatro a serviço dos homens que pretendem determinar o seu próprio destino. Assim como o Diálogo... de Galileu Galilei, os diálogos de Brecht acontecem em quatro noites. Mas Brecht optou por quatro personagens principais: o filósofo, o dramaturgo, a atriz e o ator. Além destes personagens, há os que compõem as peças de exercício para atores. Não se pode dizer que os personagens correspondam aos amigos de Brecht, mas há textos que compõem A compra do latão em que Brecht se refere a profissionais de sua equipe, como Helene Weigel e Gaspar Neher. Do mesmo modo que no Diálogo..., a concepção de Galileu Galilei se faz presente nas falas de Salviati; o 'filósofo' seria o porta-voz de Brecht. Passemos a um trecho de A compra do latão (Brecht, 1999, p. 62-3):

Filósofo - As experiências no Teatro Globe, como as de Galileu, que tinha sua maneira de tratar o globo, correspondiam a uma transformação do próprio globo. A burguesia dava os seus primeiros passos hesitantes (...). As novas idéias burguesas de Hamlet são uma doença de Hamlet. As experiências levam-no dire-tamente à catástrofe.

Dramaturgo - Indiretamente, não diretamente.

Filósofo - Está bem, indiretamente. A peça tem qualquer coisa da durabilidade do provisório, e para a conservar é sem dúvida necessário resolvê-la; dou-te razão. 
Ator - Detesto todas estas conversas sobre a arte como servidora da sociedade. Temos aí a sociedade todo-poderosa, e a arte não faz parte dela, só lhe pertence, é sua criada de mesa. Temos todos de ser criados? Não podemos ser todos senhores? A arte não pode ser uma senhora? Acabemos com os criados, também na arte!

Filósofo - Bravo!

Dramaturgo - Que quer dizer esse "bravo"? Arruínas tudo o que disseste com este grito de aclamação descontrolado. Basta que alguém venha e se diga oprimido, e já estás ao seu lado.

Galileu Galilei, ao tentar demonstrar que o mundo não deve ser visto como imutável, redigiu em seu Diálogo (Sobel, 2000, p. 147):

Sagredo - (...) Os que tanto exaltam a incorruptibilidade, a inalterabilidade etc. são induzidos a falar desse modo, creio eu, por seu grande desejo de continuar vivendo e pelo pavor que têm da morte. Esses indivíduos não cogitam que, se o homem fosse imortal, eles nunca teriam vindo ao mundo. Tais pessoas merecem realmente encontrar uma cabeça de Medusa que as transforme em estátuas de mármore e de diamante, o que as tornaria mais perfeitas do que são.

Os diálogos de Brecht foram encenados postumamente no Berliner Ensemble, sob o título de Noite Brechtiana $n^{\circ}$ 3, em 12 de outubro de 1963. Já a publicação do Diálogo (...) levou Galileu Galilei a ser condenado pela Igreja, em 22 de junho de 1633 . O cientista foi punido com a prisão domiciliar, tendo sido obrigado a abjurar publicamente as suas teorias. Mas Brecht manteve o diálogo com Galileu Galilei ao longo de praticamente toda a sua obra, seja elaborando as diferentes versões da peça sobre o cientista, seja dedicando-se à concepção de $A$ compra do latão, ou mesmo tentando agregar características da metodologia científica ao seu teatro. $\mathrm{O}$ pensamento aristotélico no campo da ciência confere aos componentes do universo o caráter de desenvolvimento natural e inato, ao qual Galileu Galilei se opôs, na medida em que fundamentou sua concepção de ciência em cálculos matemáticos e na utilização de instrumentos. Ao apontar o telescópio para a Lua, Galileu Galilei identificou crateras e montanhas na superfície lunar, semelhantes às da Terra. Por meio do telescópio e da matemática também pôde observar Júpiter e calcular o movimento de seus satélites. Com a incorporação de cálculos e de instrumentos à pesquisa científica, o mundo supralunar apresentava-se aos olhos do cientista tão mutável e imperfeito quanto a Terra. A nova metodologia de Galileu Galilei contrariou o saber vigente de modo irreversível, comprovando que Aristóteles, nesse campo, estava errado.

Chassot (1994, p. 44) explica sucintamente o chamado pensamento orgânico de Aristóteles. Para o filósofo grego, 
todos os seres tinham o seu lugar natural. Assim, o lugar dos materiais terrestres era o centro da Terra, e quanto mais elemento terra um corpo tivesse, mais fortemente ele procuraria chegar até lá. Dessa forma, as coisas mais pesadas, isto é, mais grávidas de terra, cairiam mais depressa que as mais leves. O lugar natural das águas é sobre a superfície da Terra, cobrindo-a como um cobertor. O lugar natural do elemento fogo é na esfera acima de nossas cabeças, e, já que o fogo quer retornar para a sua morada, vemos as chamas queimarem para cima.

Assim como Galileu Galilei, que no campo da ciência rompeu com o modelo Aristotélico, Brecht, no campo artístico-teatral, procurou romper com a herança aristotélica no sentido de abolir de seu teatro a empatia e a catarse, conceituadas por Aristóteles em sua Poética. Brecht (1967, p. 175) afirmou:

O abandono da empatia não se origina de um abandono das emoções e não leva a isto. A tese da estética vulgar de que somente podem ser criadas emoções através da empatia é uma tese errada. Em todo o caso, uma dramática não-aristotélica tem que se submeter a uma crítica cuidadosa quanto às emoções que pretende criar e que estão contidas nela.

Rompendo, portanto, com a tradição que ele próprio chamou de aristotélica, Brecht inaugurou um novo teatro, que batizou de 'teatro épico', transformando-se em um dos mais importantes dramaturgos e encenadores do século XX.

Sobre esse aspecto, Jean-Jacques Alcandre (1999, p. 19) afirmou que "Brecht abordou conscientemente sua época como um Galileu dos tempos modernos. É preciso lembrar que Brecht e Galileu lutam, cada qual em seu domínio, contra a tradição aristotélica". O nome que Brecht escolheu para designar o teatro que ele pretendia desenvolver traz, em si, segundo o próprio dramaturgo, uma oposição a Aristóteles. Em um de seus escritos, Brecht (1978, p. 46) afirma: "a expressão 'teatro épico' pareceu a muitos contraditória em si, pois, a exemplo de Aristóteles, considerava-se que a forma épica e a forma dramática de narrar uma fábula eram fundamentalmente distintas uma da outra". Ao formular a teoria do teatro épico, Bretch buscava a contaminação de gêneros que tradicionalmente eram considerados mutuamente excludentes. Na verdade, o conceito brechtiano de teatro aristotélico abrangia todo tipo de teatro em que prevalecesse a identificação na relação palco-platéia. Brecht desenvolveu, então, novas técnicas de representação, que sistematizou em obras teóricas como, por exemplo, Cena de rua (1940). Neste texto, o dramaturgo propõe um modelo concreto para seu novo teatro - a cena de rua: 
É relativamente fácil apresentar um esquema de teatro épico. Para trabalhos práticos, eu escolhia, habitualmente, como exemplo de um teatro épico mais insignificante (...) um acontecimento que se pudesse desenrolar em qualquer esquina de rua: a testemunha ocular de um acidente de trânsito mostra a uma porção de gente como se passou o desastre. $\mathrm{O}$ auditório pode não haver presenciado a ocorrência, ou pode, simplesmente, não ter um ponto de vista igual ao narrador. (...) o fundamental é que o relator reproduza a atitude do motorista ou a do atropelado, ou de ambos, de tal forma que os circunstantes tenham possibilidade de formar um juízo crítico sobre o acidente. Este exemplo de um teatro épico na sua forma primitiva parece ser, em si, facilmente aceitável. No entanto, pelo que sabemos por experiência própria, tal exemplo reveste-se, para o ouvinte ou leitor, de uma espantosa dificuldade, desde que ou a um ou a outro se exija que compreenda, em todo o seu alcance, o propósito a que obedeceu a nossa escolha: considerar o exemplo da esquina de rua a base de um grande teatro, um teatro de uma época científica. O que com isso se pretende dizer é, por um lado, que o teatro épico pode nos surgir, em todos os seus pormenores, como um teatro mais rico, mais complexo, mais evoluído, mas que não tenta incluir, fundamentalmente, nenhum elemento que vá além desta exemplificação da esquina de rua, para poder ser um grande teatro; e, por outro lado, não se poderia chamar teatro épico se faltassem alguns dos elementos essenciais (Brecht, 1978, p. 67).

A partir do exemplo da cena de rua, Brecht formula com clareza alguns dos elementos indispensáveis do teatro épico, como por exemplo a necessidade de o ator citar o seu personagem, sem nunca com ele se identificar. Brecht também se refere nesse texto à estrutura e aos objetivos de seu teatro épico, fundamentado no efeito de distanciamento (Verfrendungseffekt) ou, como também é conhecido, 'Efeito V'.

O aspecto prático da ciência de Galileu Galilei nos aponta também para uma ligação entre ciência e técnica. A ciência de Galileu é considerada por muitos historiadores da área como a ciência do engenheiro ou artesão. Um dos mais respeitados biógrafos do cientista italiano, Stillman Drake (1957, p. 5), afirma que "Galileu tinha prazer em conversar com artesãos e aplicar sua ciência aos problemas práticos deles". O historiador da ciência Claude Chrétien (1994, p. 63) explica: "É certo que os fundadores da ciência moderna são engenheiros, inventores e empreendedores (Leonardo da Vinci, Cardan, Benedetti, Stevin... e antes deles Arquimedes) ou estão ligados ao ambiente dos técnicos e atentos a seus trabalhos (Galileu, Descartes, Huyghens...)”. O filósofo Antônio Banfi (1992, p. 17) também comenta a relação da ciência de Galileu Galilei com a técnica: 
Mas a sua atenção dirigiu-se em particular (...) para um outro campo de estudos que a tradição universitária não reconhecia, mas que correspondia à exigência da renovada vida civil (...) e à própria natureza do engenho de Galileu que daí poderia esperar triunfos e fortuna. Tratava-se dos estudos voltados para a solução de problemas técnicos - de mecânica, de hidráulica e balística - segundo os métodos matemáticos.

Podemos dizer que tanto o método de Brecht quanto o de Galileu Galilei oferecem uma nova relação entre teoria e prática, bem como associam a atividade prática com o desenvolvimento técnico. Como vimos, tal associação fez com que historiadores da área científica caracterizassem a ciência de Galileu Galilei como ‘a ciência do engenheiro'. Neste aspecto, identificamos outro ponto de contato entre a ciência de Galileu Galilei e o teatro de Brecht. Walter Benjamim, em seu ensaio 'O autor como produtor', analisa a função dos autores na sociedade de sua época, enfocando a distinção entre os que abastecem o aparelho literário dominante e os que produzem novas técnicas. Para Benjamin, o 'autor produtor' é aquele que, assim como um engenheiro, constrói novas técnicas e estruturas. Benjamin associou Brecht a um 'engenheiro', na medida em que ele imprimiu em sua escrita dramatúrgica e cênica novas técnicas e formas, que transformariam a estrutura da produção e da recepção teatrais. Isto porque os textos e as cenas de Brecht propõem mecanismos que alteram as relações funcionais entre palco e platéia, diretores e atores, e texto e representação. A esse respeito Benjamin (1987, p. 132) afirmou:

Um escritor que não ensina outros escritores não ensina ninguém. O caráter modelar da produção é, portanto, decisivo: em primeiro lugar, ela deve orientar outros produtores em sua produção e, em segundo lugar, precisa colocar à disposição deles uma aparelho mais perfeito. Esse aparelho é tanto melhor quanto mais conduz consumidores à esfera da produção, ou seja, quanto maior for a sua capacidade de transformar em colaboradores os leitores ou espectadores. Já possuímos um modelo desse gênero, do qual só posso falar aqui rapidamente. É o teatro épico de Brecht.

Pode-se dizer ainda que Brecht pretendeu incorporar ao seu teatro esse comportamento de Galileu Galilei, no que diz respeito à dúvida sobre o óbvio. Por meio de uma fala do protagonista da peça Vida de Galileu, citada em um de seus escritos, Brecht caracteriza a ciência de Galilei Galilei como uma atitude de dúvida e questionamento ou, como provavelmente preferiria dizer, uma atitude de estranhamento diante de circunstâncias familiares. 
Galileu - O homem que pela primeira vez olhou com espanto uma lâmpada balançando numa corda, e em vez de achar isto muito natural, achou muito significativo que ela se balançasse daquela e não de outra maneira, aproximou-se muito da compreensão do fenômeno e da maneira de como dominá-lo. Não, eu não estou falando de esperteza. Eu sei que na hora de comprar o homem chama o cavalo de burro e o burro de cavalo na hora de vender. Agora, o navegador que provê seu barco pensando na tempestade e na calmaria. A velha que dá mais capim a sua mula porque sabe que no dia seguinte vão viajar. $O$ menino que bota $o$ boné porque lhe provaram que pode chover. Estes são a minha esperança. Sim, eles usam a cabeça. Pensar é um dos maiores prazeres da raça humana (Brecht, 1977b, p. 59).

Os conhecimentos científicos contribuíram para a formulação do teatro épico. Mas certamente o teatro épico de Brecht também constitui contribuição fundamental para a ciência. Para citar uma delas, podemos dizer que nessa concepção de teatro o cientista ganha osso, carne, sangue, rosto, corpo, contradições, amores, decepções, conquistas, infidelidades - como é o caso de Galileu Galilei. Enfim, o teatro confere 'humanidade' ao cientista. Nos tempos em que o 'cientificamente comprovado' é o conhecimento inquestionável, a ciência é vista muitas vezes como se fosse uma profissão de fé e, nesse sentido, camufla a humanidade deste protagonista da sociedade atual - o cientista.

\section{Alguns papéis da arte em museus científicos: a experiência do Ciência em Cena}

A poesia é indispensável. Se eu ao menos soubesse para quê... (Jean Cocteau, apud Ernest Fischer, 1987, p. 11.)

Para que serve a arte? Qual é o papel da arte na sociedade? Ernest Fischer (1987, p. 13), na obra A necessidade da arte, reflete:

O homem anseia por absorver o mundo circundante, integrá-lo a si; anseia por estender pela ciência e pela tecnologia o seu 'Eu' curioso e faminto de mundo até as mais remotas constelações e até os mais profundos segredos do átomo; anseia por unir na arte o seu 'Eu' limitado com uma existência humana coletiva e por tornar social a sua individualidade. Se fosse da natureza do homem o não ser ele mais do que indivíduo, tal desejo seria absurdo e incompreensível, porque então como indivíduo ele já seria um todo pleno, já seria tudo que era capaz de ser. O desejo do homem de se desenvolver e completar indica que ele é mais que um indivíduo. Sente que só pode atingir a plenitude se se apoderar das experiências alheias que potencialmente lhe concernem, que po- 
deriam ser dele. E o que um homem sente como potencialmente seu inclui tudo aquilo que a humanidade, como um todo, é capaz. A arte é o meio indispensável para essa união e do indivíduo com o todo; reflete a infinita capacidade para a associação, para a circulação de experiências e idéias.

Fischer apresenta a arte como forma de colocar o homem em estado de equilíbrio com o mundo à sua volta, daí viria a necessidade da arte. Aprofundar a discussão sobre o papel ou a função da arte na sociedade atual é exercício filosófico que, apesar de instigante, não caberia no presente artigo. Entretanto, Fischer nos oferece um bom ponto de partida para a reflexão sobre alguns possíveis papéis das artes em museus de ciência. Claude Lévi-Strauss (1970), em La pensée sauvage, também estimula a discussão. Segundo o antropólogo francês, o cientista nunca dialoga com a natureza pura, mas com um certo estado de relação entre a natureza e a cultura, definível pelo período da história em que vive, sua civilização, os materiais dos quais dispõe. Talvez seja na relação entre ciência e sociedade que a arte possa dar uma contribuição relevante aos museus de ciência, uma vez que, por meio da linguagem artística, é possível apresentar acontecimentos da ciência e da vida de cientistas, relacionando-os ao ambiente social em que estão inseridos. O teatro, por exemplo, pode contextualizar social, histórica e politicamente a prática científica, concretizando episódios do mundo real e reproduzindo com riqueza de informações diferentes circunstâncias. A convicção de que o teatro pode contribuir para o processo educativo é antiga e pode ser constatada já na Arte poética de Aristóteles - um dos mais antigos registros sobre o teatro ocidental. Ao longo da história do teatro, verificamos muitos momentos em que a associação entre teatro e educação esteve presente de diferentes maneiras e em níveis diversos. O teatro da Idade Média se serviu da linguagem teatral para ensinar a vida dos santos por meio dos mystères franceses ou das sacri rappresentazioni italianas. A Igreja encenava os sacramentos em espetáculos que se multiplicaram pela Europa e alcançaram grande popularidade. Na Renascença, os estudiosos das obras clássicas encenavam peças latinas e almejavam 'reencenar' a cultura greco-romana por meio do teatro. No século XX, o chamado living newspaper, nos Estados Unidos, empregava fontes documentais como material dramático e tinha como meta a educação política.

No período entre 1960 e 1970, o diretor Augusto Boal realizou experiências teatrais no Brasil e em outros países da América Latina que objetivavam a educação política por meio de um teatro interativo. O Teatro de Arena de São Paulo e os Centros Populares de Cultura (CPCs) também devem ser mencionados como importantes iniciativas brasileiras no campo do teatro como educação política. O teatro 
pode ainda contar a história da ciência e apresentar o cientista como um homem comum que possui contradições, desejos e qualidades, e não como uma figura mítica e inacessível, que, por meio de uma suposta genialidade, alcançaria os mais importantes conhecimentos. A presença física dos atores, característica da linguagem teatral, contribui para aproximar a assistência dos temas apresentados. Por meio do teatro é possível recriar não apenas um episódio da ciência em si, mas também seus antecedentes, conseqüências e influências com riqueza de detalhes, o que é devido, entre outras razões, ao uso simultâneo de variadas linguagens como a cenografia, a música ou a iluminação. Alguns museus, centros de ciência e universidades incluíram peças ou recursos teatrais em sua programação, tais como o Museu da Vida, o Estação Ciência e a Universidade Federal do Espírito Santo. O Museo de La Luz utiliza uma ambientação cenográfica batizada como 'Cemitério das teorias mortas', em que há um cemitério cenográfico com lápides em que estão inscritos os nomes de teorias ultrapassadase as datas em que vigoraram. O Museu de Boston fundou uma associação, a International Museum Theatre Alliance, para o desenvolvimento de um programa que discute o teatro como recurso educativo.

Em um museu de ciência, o teatro, além de transmitir conteúdos do campo científico, pode contribuir para despertar o interesse pela ciência e pela arte. Os questionamentos clássicos que intrigam o homem e que muitas vezes o movem em direção às ciências são teatrais por natureza. De onde viemos? Para onde vamos? Estas são perguntas a que Darwin e Galileu tentaram responder, mas a que Calderón de La Barca e Sófocles responderam na liberdade de sua poesia dramatúrgica.

Mas seria o papel de um museu de ciências despertar o gosto pelas artes? Talvez não, mas quando se inclui a arte como discurso, necessariamente este discurso falará dela também. A encenação de uma peça sobre Galileu Galilei, por exemplo, estará transmitindo conteúdos relacionados à vida e à obra do cientista, mas ao mesmo tempo estará transmitindo um determinado modo de fazer teatro que se comunica por si só, independentemente do conteúdo científico exibido. A arte, portanto, nunca será apenas ferramenta, ainda que se quisesse - e não queremos, deixemos claro. Devemos atentar, entretanto, para o fato de que há alguma especificidade no exercício do teatro em um museu de ciências.

Tomemos por base a experiência desenvolvida no Ciência em Cena. Os principais objetivos deste espaço, concebido originalmente por Virgínia Schall, são a pesquisa sobre ciência e arte e o desenvolvimento de atividades artísticas que promovam a apresentação e discussão de temas da ciência. Hoje, o Ciência em Cena conta com uma equipe multidisciplinar formada por profissionais das áreas de artes, ciências, pedagogia e técnicos. Em termos de instalações e equipa- 
mentos, o espaço consta de um cine-teatro para duzentas pessoas (Tenda do Ciência em Cena), um anfiteatro para quarenta pessoas (Epidaurinho), dois palcos externos, uma ilha de edição e equipamentos de filmagem. Na programação de atividades, múltiplos recursos artísticos são explorados, tais como vídeo, artes plásticas e, principalmente, o teatro. Quando se utiliza a linguagem teatral com o objetivo de veicular conceitos do campo das ciências ou despertar vocações científicas, é preciso desenvolver instrumentos de aferição de aprendizagem. Para o espetáculo O mensageiro das estrelas, de Ronaldo Nogueira da Gama, que cumpriu temporada de 1998 a 2001 e recebeu mais de 16 mil espectadores na Tenda do Ciência em Cena, foi desenvolvido um roteiro de sugestões de atividades teatrais a serem desenvolvidas em sala de aula pelo professor, com o objetivo de fixar os conteúdos apresentados na peça e de multiplicar os efeitos do espetáculo. Após a peça realizava-se um debate com os atores, com físicos e o público. Nesse momento o público tinha a oportunidade de esclarecer dúvidas e fazer comentários e sugestões. No fim da temporada algumas escolas visitantes foram convidadas a retornar ao Ciência em Cena para apresentar os trabalhos desenvolvidos na escola e assumirem o palco. Foram apresentados desenhos de cenas sobre o cientista italiano, redações sobre a peça, poesias sobre Galileu e performances teatrais sobre a temática da peça e outros temas como drogas, ecologia e sexo seguro. A experiência desse espetáculo pode ser detalhadamente conhecida no artigo ‘Discutindo ciência em cena por meio do teatro' (Lopes, 1999, 2000).

O Ciência em Cena apresenta a peça Lição de botânica, escrita por Machado de Assis em 1906, e dirigida por Gustavo Ottoni. No texto, Machado aborda com delicadeza e ironia a relação entre ciência e sentimentos. Outra peça em cartaz é O mistério do barbeiro, dirigida por Jacyan Castilho, sobre a descoberta da doença de Chagas. Além da apresentação de peças de teatro, há improvisações teatrais e jogos dramáticos que relacionam biologia e cultura em atividade intitulada Laboratórios de percepção. Nesta atividade o visitante é convidado a conhecer conteúdos relativos aos sentidos humanos por meio de uma exposição interativa e a refletir, por meio da realização de improvisações, sobre como a cultura e a emoção influenciam a organização das informações apreendidas pelos sentidos. $\mathrm{O}$ visitante troca de lugar com os atores e ganha o palco vivenciando o processo de criação artística. As improvisações são orientadas por profissionais da área de artes que contam com máscaras teatrais, peças de figurino, iluminação cênica e trilha sonora. As improvisações podem estar relacionadas também aos instrumentos ópticos, como caleidoscópios gigantes e jogo de sombras, também disponíveis nos Laboratórios de percepção.

Outra linguagem artística utilizada no Ciência em Cena é o vídeo. No projeto Videoclube do Futuro (VCF), há uma intensa articula- 
ção com o ensino formal. Antes de realizar a atividade do VCF, os professores participam de uma oficina, ministrada pela equipe do Ciência em Cena, em que são preparados para orientar seus alunos. Na oficina eles recebem informações sobre o manuseio de equipamentos de filmagem, noções de interpretação e enquadramento, concepção de roteiros, por exemplo. Após a oficina, os professores multiplicam as informações entre os seus grupos de alunos e agendam uma visita ao VCF para a realização de um vídeo de curta duração sobre temas relacionados à saúde e a outros temas de interesse. Em atividade com duração de aproximadamente seis horas, os alunos se dividem em funções e vivenciam todas as etapas de produção de um vídeo - desde a concepção do roteiro até a edição e a produção final. A linguagem do vídeo é discutida nas oficinas e ao longo do processo de concepção do vídeo, relacionando conceitos de percepção, óptica, acústica e questões referentes à ética da informação e às diferentes versões que um fato (científico ou não) pode ter, dependendo da linguagem que se utilize.

A utilização do vídeo se estende em mais duas atividades no Ciência em Cena: o Videodebate - como o próprio nome revela, constitui-se da exibição de vídeo seguida de debate com profissionais especializados que estimulam e explicitam questões relativas ao conteúdo apresentado - e a Arte e ciência de perceber - atividade em que se mesclam vídeo e artes plásticas e em que se exibem imagens de obras de Picasso, Portinari, Monet, entre outros pintores, com o objetivo de discutir diferentes pontos de vista e percepção do mundo.

A partir de nossa experiência no Ciência em Cena, podemos refletir um pouco sobre como, no cotidiano de um museu de ciências, a interação entre arte e ciência pode se dar em diferentes níveis e modalidades. Com essa experiência, podemos também chegar a algumas conclusões. A arte pode ajudar a popularizar a ciência porque pode contribuir para conferir emoção aos temas da ciência. $\mathrm{O}$ registro dito científico não incorpora a emoção da atividade científica. Embora a ciência seja emocionante, os textos científicos, por exemplo, não incluem a emoção da descoberta, a paixão pelo fazer científico; não são emocionados, por isso não emocionam. A ciência é emocionante, mas o registro que se faz dela é, na maior parte das vezes, muito frio e não inclui o papel da intuição na prática científica - o que acentua a errônea visão dicotômica de que a ciência se baseia na razão e a arte na emoção. Hoje reconhece-se que há sistematização de métodos no fazer artístico e que a arte não é puramente emoção ou subjetividade, mas a idéia da razão versus emoção ainda nos ronda. A arte pode ampliar níveis de interação nos museus, na medida em que pode propor a vivência de processos criativos. Conclui-se ainda que é importante ser realizada por uma equipe de cientistas em conjunto com artistas profissionais que 
possam conceber atividades com bom acabamento estético, principalmente porque em nosso país, na grande maioria das vezes, a visita ao museu proporciona o primeiro contato mais intenso com a atividade artística. É importante também promover a articulação das atividades com o ensino formal devido à escassez de informações no campo da ciência e da arte.

\section{Mas afinal, por que arte e ciência? Para o caso de ainda haver dúvidas...}

Mas que tem ciência a ver com a arte?

Sabemos perfeitamente que a ciência pode ser motivo de diversão, mas nem tudo o que diverte tem cabimento num palco.

(Brecht, 1967, p. 99.)

É preciso beber na arte e na ciência para aprender a estranhar o habitual, para enxergar no óbvio o inusitado. As grandes descobertas surgiram do espanto diante do óbvio. Galileu Galilei tira a Terra do lugar porque duvida de que é o Sol que anda, apesar da nítida sensação de que é ele que se move sobre nossas cabeças. Van Gogh também não se contentou com o óbvio e fez nascer girassóis de todos os amarelos, até aqueles que nunca veremos em plantação alguma. Girassóis que transbordam da tela de tão amarelos que são. Salve Van Gogh, que fez os girassóis pularem em nosso colo. Van Gogh que anoitece o céu de Galileu a qualquer hora do dia, que pode nos dar uma noite estrelada em pleno meio-dia. Van Gogh viu diferente. Galileu viu diferente. Que eles, juntos, nos inspirem a ver e fazer um mundo diferente.

Equipe do Ciência em Cena

Consultoria científica - Virgínia Schall

Coordenação - Thelma Lopes

Mediadores - Gustavo Ottoni, Luciana Sales, Luís Carlos Victorino, Luís Fernando

Donadio, Maria do Rosário de A. Braga e Rosicler Neves

Equipe técnica - Adroaldo Gonçalves, André Freitas, Armando Feitosa, Rafael

Gambetá e Ronaldo Barboza

A equipe conta ainda com estagiários e monitores 


\section{REFERÊNCIAS BIBLIOGRÁFICAS}

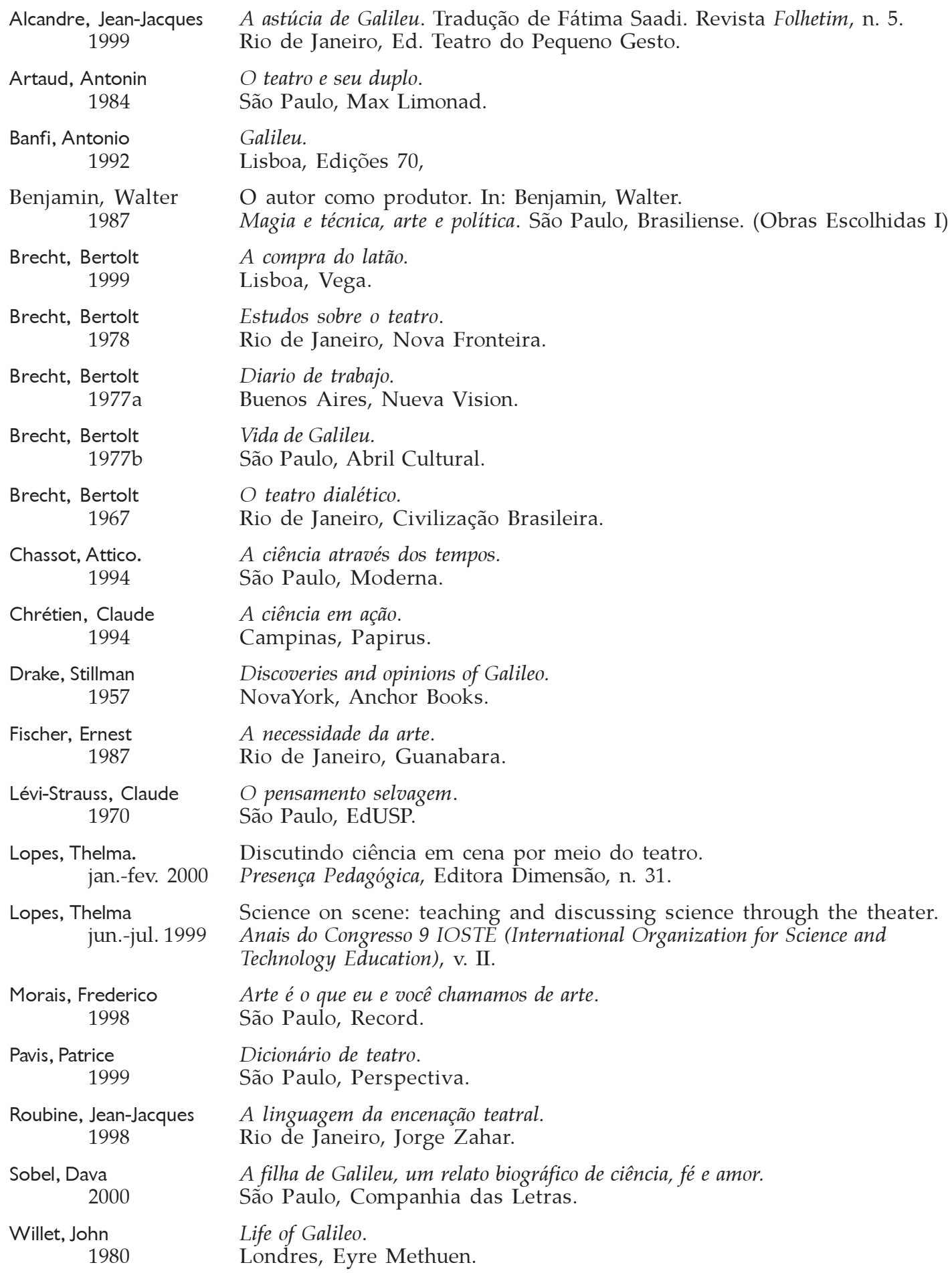

Recebido para publicação em abril de 2003. Aprovado para publicação em novembro de 2004. 